\title{
A comparison of the remineralizing potential of dental restorative materials by analyzing their fluoride release profiles
}

\author{
Alicja Porenczuk ${ }^{1, A-D}$, Bartłomiej Jankiewicz ${ }^{2, A, D, E}$, Magdalena Naurecka ${ }^{3, B, C}$, Bartosz Bartosewicz ${ }^{2, A, B}$, \\ Bartosz Sierakowski ${ }^{3, B, C}$, Dariusz Gozdowski ${ }^{4, C}$, Jerzy Kostecki ${ }^{5, B}$, Barbara Nasiłowska ${ }^{3, B}$, Agnieszka Mielczarek ${ }^{1, A, E, F}$ \\ ${ }^{1}$ Restorative Dentistry Department, Warsaw Medical University, Poland \\ ${ }^{2}$ Institute of Optoelectronics, Military University of Technology, Warszawa, Poland \\ ${ }^{3}$ Biomedical Engineering Center, Institute of Optoelectronics, Military University of Technology, Warszawa, Poland \\ ${ }^{4}$ Faculty of Agriculture and Biology, Department of Experimental Design and Bioinformatics, Warsaw University of Life Sciences, Poland \\ ${ }^{5}$ Electron Microscopy Laboratory, Institute of Optoelectronics, Military University of Technology, Warszawa, Poland \\ A - research concept and design; $B$ - collection and/or assembly of data; $C$ - data analysis and interpretation; \\ $D$ - writing the article; $E$ - critical revision of the article; $F$ - final approval of the article
}

Address for correspondence

Alicja Porenczuk

E-mail: alicja.porenczuk@gmail.com

\section{Funding sources}

The study was supported by grant No. WUM 1S18/PM2/17 from Warsaw Medical University, Poland.

\section{Conflict of interest}

None declared

\section{Acknowledgements \\ The authors would like to express their gratitude to Miron Kaliszewski and Maksymilian Włodarski (Institute of Optoelectronics, Military University of Technology, Warszawa, Poland) for constructing the $3 D$ forms used in the study.}

Received on March 8, 2018

Reviewed on May 3, 2018

Accepted on August 9, 2018

Published online on February 8, 2019

Cite as

Porenczuk A, Jankiewicz B, Naurecka M, et al. A comparison of the remineralizing potential of dental restorative materials by analyzing their fluoride release profiles. Adv Clin Exp Med. 2019;28(6):815-823. doi:10.17219/acem/94140

DOI

10.17219/acem/94140

Copyright

Copyright by Author(s)

This is an article distributed under the terms of the

Creative Commons Attribution Non-Commercial License

(http://creativecommons.org/licenses/by-nc-nd/4.0/)

\begin{abstract}
Background. The accessibility of the remineralizing ions in teeth's environment is essential for their incorporation into caries-affected dentin. Novel bioglass-reinforced materials capable of releasing fluoride, calcium and phosphates may be particularly useful in the tissue remineralization process. A novel restorative material, ACTIVA BioActive-Restorative (Pulpdent Corp., Watertown, USA), is a hydrophilic resin-modified glassionomer cement (RMGIC) enriched with bioglass particles and fortified with a patented rubberized polymer resin. Its application in restorative dentistry may be significant, promoting remineralization of carious lesions.

Objectives. The aim of the study was to compare the fluoride ion release profiles from a bioglass-reinforced RMGIC, a conventional glass-ionomer cement $(G I C)$ and a nanohybrid restorative polymer resin.

Material and methods. The quantity of fluoride ions released from ACTIVA, Ketac Molar Quick Aplicap and Tetric EvoCeram was assessed using a fluoride-specific electrode. The surface characteristics of the preand post-experimental specimens were studied using a scanning electron microscope (SEM) and confocal microscope. An X-ray powder diffraction (XRD) analysis was additionally used to examine the chemical compositions of the dental materials.
\end{abstract}

Results. The greatest quantity of fluoride ions was freed from the GIC specimens (20.698-54.118 ppm), followed by the bioglass-reinforced RMGIC (from 1.236 to 15.552 ppm) and nanohybrid polymer resin (0.370-1.148 ppm). The pre-experimental specimens of the bioglass-reinforced RMGIC were porous, while the post-experimental specimens were smoother with visible micro-cracks. The XRD analysis of the bioglass particles confirmed that the material was composed mainly of fluoride (27.70 mass\%), silicon (15.62 mass\%), aluminum (5.91 mass\%), and calcium (5.40 mass\%).

Conclusions. The fluoride ion release profile of ACTIVA was lower than the GIC Keta Molar Quick Aplicap, but significantly higher than the nanohybrid restorative polymer resin Tetric EvoCeram.

Key words: fluoride, scanning electron microscopy, bioactive glass, resin-modified glass-ionomer cement, confocal microscopy 
The principle underlying minimally invasive dentistry is the introduction of clinical procedures that contribute to the restoration of carious tissues. The remineralization process entails incorporating fluoride, calcium and phosphate ions into demineralized tissues. In deep cavities which are in need of endodontic treatment, partially demineralized dentin may remain at the bottom of the cavity as long as it is hermetically sealed off from the outer environment with bioactive restorative materials (biomaterials). Bioactivity, according to Hench, is the capacity of the dental material to join with living tissue without causing any adverse effects. ${ }^{1}$ After placement in the cavity, the process of "bioactive fixation" occurs, in which the biomaterial interacts chemically with the constituents of the tissue, creating a homogenous mass. ${ }^{2}$ The most important feature in the remineralizing potential of a biomaterial is its ability to release fluoride ions. In an ionized form, fluoride can easily be exchanged with the hydroxyl ions in hydroxyapatite, leading to the formation of the fluorohydroxyapatite crystal (FHA; general chemical structure $\mathrm{Ca}_{5}\left(\mathrm{PO}_{4}\right)_{3} \mathrm{OH}_{1-}$ $\left.{ }_{\mathrm{x}} \mathrm{F}_{\mathrm{x}}\right)$. The FHA, being resistant to acid demineralization promoted by caries-associated bacteria, is chemically more stable than other hydroxyapatite forms. ${ }^{3}$ Moreover, it acts as a reservoir for fluoride ions, releasing them when the $\mathrm{pH}$ in the surrounding environment falls below 4.5. ${ }^{3}$ The FHA thus protects dental tissues from further acidic degradation. Biomaterials include glass-ionomer cements (GICs) and their derivatives, such as resin-modified glass ionomer cements (RMGICs) and bioglass restoratives - a novelty in restorative dentistry - made from $\mathrm{SiO}_{2}-\mathrm{CaO}-\mathrm{Na}_{2} \mathrm{O}-\mathrm{P}_{2} \mathrm{O}_{5}$ components. Stress-bearing cavities would normally be restored with resin-based polymer materials. Although they may contain fluoride in the form of the radiopaque filler ytterbium trifluoride $\left(\mathrm{YbF}_{3}\right)$, its release seems insufficient for remineralization. ${ }^{4}$ Glass-ionomer cements and their derivatives should therefore be applied in all situations where tissue repair is required. ${ }^{5}$ They owe their ability to release ions to their silicate filler content, which continuously releases and recharges fluoride, and to their structural inner porosity, which allows water to flow through the material, leading to the dissolution of the filler. However, biological features of GICs may impair their physical properties, making them brittle and necessitating their replacement. ${ }^{4}$ The development of RMGICs was a response to an urgent need for GICs with enhanced mechanical properties. They contain the same filler as GICs, a water-soluble matrix formed by poly(acrylic acid) and organic monomers, such as 2-hydroxyethyl methacrylate (HEMA), taken from polymer resins. ${ }^{6}$ Their hydrophilic character, provided by HEMA, improves the water uptake and the dissolution of the filler, along with the release of the desired fluoride ions. ${ }^{7}$ Straightforward as this may seem, the level of the fluoride ions liberated from RMGICs is less than GICs, which may be presumed a result of the HEMA altering the acidbase reaction and leading to the formation of a weaker gel network. ${ }^{5,6}$ Nevertheless, RMGICs have sufficient physical endurance to be used as a restorative material in deep cavities, and as an alternative to polymer resins.

Recently, continuing progress in the development of dental materials and the search for more efficient biomaterials has led to the incorporation of $\mathrm{SiO}_{2}-\mathrm{CaO}-\mathrm{Na}_{2} \mathrm{O}-\mathrm{P}_{2} \mathrm{O}_{5}$ bioglass particles in the polymer matrix. The mechanism of bioglass dissolution is facilitated by the breakup of the $\mathrm{Si}-\mathrm{O}-\mathrm{Si}$ bonds in the silicate network in an aqueous environment, which permits the rapid release of fluoride, calcium and silicon. ${ }^{5}$ Hydroxyl ions are also released, leading to the alkalization of the environment as well as eradication of the bacteria. ${ }^{8}$ The structure of a bioglass restorative may determine its bioactivity, as its inner porosity facilitates water flow through the material and the dissolution of the bioglass. ${ }^{9}$ Although the hydrophilic nature of this material is attributable to HEMA, the amount of bioglass added should be carefully judged. According to Khvostenko et al., approx. 15 weight percentage (wt\%) is adequate to obtain the desired properties. ${ }^{10}$

The recently introduced ACTIVA BioActive-Restorative (Pulpdent Corp., Watertown, USA) is a hydrophilic RMGIC enriched with bioglass and fortified with a patented rubberized polymer resin. The material contains both bioglass particles and polyacid components of RMGICs. The material does not contain bis-GMA, bisphenol A (BPA) or BPA derivatives, and is therefore considered more biocompatible than other resin-based materials. According to the manufacturer, the triple setting mode of this material includes the acid-base neutralization reaction of GICs, self-cure and light-cure of the matrix. Recent studies have shown its ability to release remineralizing ions without adverse effects on its physical durability. ${ }^{11}$ However, its exact chemical composition and structure have not been disclosed by the manufacturer.

\section{Objectives}

The aim of the study was to compare the fluoride ion release profiles of a bioglass-reinforced RMGIC, a conventional GIC and a nanohybrid restorative polymer resin. The null hypothesis stated that the bioglass-reinforced RMGIC releases quantities of fluoride ions comparable to the GIC.

\section{Material and methods}

\section{Material}

The characteristics of the dental materials used in the study, according to the data provided by the manufacturers, are presented in Table 1. Sodium fluoride (NaF) was obtained from POCH S.A. (Gliwice, Poland) and TISAB I from Hydromet S.C. (Gliwice, Poland). Deionized (DI) water $\left(0.05 \mu \mathrm{S} / \mathrm{cm}\right.$ at $25^{\circ} \mathrm{C}$; Hydrolab, Dziewięć Włók, Poland) was used throughout the study. 
Table 1. Specifications of dental materials used in the study, according to the data provided by the manufacturers

\begin{tabular}{|c|c|c|c|c|}
\hline $\begin{array}{l}\text { Material (short name, } \\
\text { shade) }\end{array}$ & Type & Composition & Setting mode & Lot number \\
\hline $\begin{array}{l}\text { ACTIVA } \\
\text { BioActive-Restorative } \\
(A B \text {, shade } A 2)\end{array}$ & $\begin{array}{c}\text { bioglass-reinforced glass- } \\
\text { ionomer restorative } \\
\text { cement }\end{array}$ & $\begin{array}{c}\text { blend of diurethane and methacrylates with } \\
\text { modified polyacrylic acid ( } 44.6 \%) \text {; reactive glass } \\
\text { filler ( } 21.8 \text { wt\%); inorganic filler ( } 56 \text { wt\%), patented } \\
\text { rubberized resin (Embrace), water }\end{array}$ & $\begin{array}{l}\text { light-cure and self-cure; } \\
\text { curing time } 20 \mathrm{~s} ; \\
\text { chemical setting (reaction } \\
\text { of neutralization) }\end{array}$ & 151217 \\
\hline $\begin{array}{l}\text { Ketac Molar Quick } \\
\text { Aplicap } \\
\text { (KM) }\end{array}$ & $\begin{array}{c}\text { glass-ionomer restorative } \\
\text { cement }\end{array}$ & $\begin{array}{l}\text { Powder: inorganic filler (calcium (Ca), aluminum (Al), } \\
\text { lanthanum (La), silicon (Si), fluorosilicate glass } \\
\text { (73-74 wt\%)); pigments. } \\
\text { Liquid: polycarboxylic acid, tartaric acid, water }\end{array}$ & $\begin{array}{l}\text { chemical setting (reaction } \\
\text { of neutralization) }\end{array}$ & 570386 \\
\hline $\begin{array}{l}\text { Tetric EvoCeram } \\
\text { (TE, shade A2) }\end{array}$ & $\begin{array}{l}\text { nanohybrid composite } \\
\text { restorative material }\end{array}$ & $\begin{array}{l}\text { dimethacrylates: bis-GMA; UDMA (19.7 wt\%); } \\
\text { inorganic filler (size } 40-3,000 \mathrm{~nm} \text {, barium glass } \\
\text { and ytterbium trifluoride (62.5 wt\%), mixed oxide, } \\
\text { prepolymer (19.7 wt\%)) }\end{array}$ & $\begin{array}{l}\text { light-cure; } \\
\text { curing time } 10 \mathrm{~s}\end{array}$ & U49869 \\
\hline
\end{tabular}

wt\% - weight percent; bis-GMA - bisphenol A glycidyl dimethacrylate; UDMA - urethane dimethacrylate.

\section{Methods}

\section{Specimen preparation}

Fifteen disc-shaped specimens of each of the 3 dental materials were prepared, 5 per group. The materials were applied to Z-ABS poly(acrylonitrile-co-butadiene-costyrene) 3D molds (Zortrax S.A., Olsztyn, Poland) and printed using an M200 printer (Zortrax S.A.). Each mold had an internal diameter of $8 \mathrm{~mm}$, height of $3 \mathrm{~mm}$ and total surface area of $175.85 \mathrm{~mm} .^{2}$ The 3D form was placed on a glass slab and, after application of the material, another glass slab was positioned over it and moderately hand-pressed in order to level up the specimen surface. Light-setting restoratives were cured using a Radii Plus diode polymerization lamp (SDI Ltd., Bayswater, Australia; light intensity $\left.1500 \mathrm{~mW} / \mathrm{cm}^{2}\right)$. The capsulated Ketac Molar Quick Aplicap (KM; 3M ESPE Dental Products, St. Paul, USA) was mechanically mixed in a Silamat Plus mixing unit (Ivoclar Vivadent, Schaan, Liechtenstein), transferred to the molds with a dedicated applier, covered with a glass slab, and left to harden (Fig. 1). After setting, the glass slabs were carefully removed and the specimens were freed from the forms with a $3 \mathrm{D}$ reverse form. In order to remove
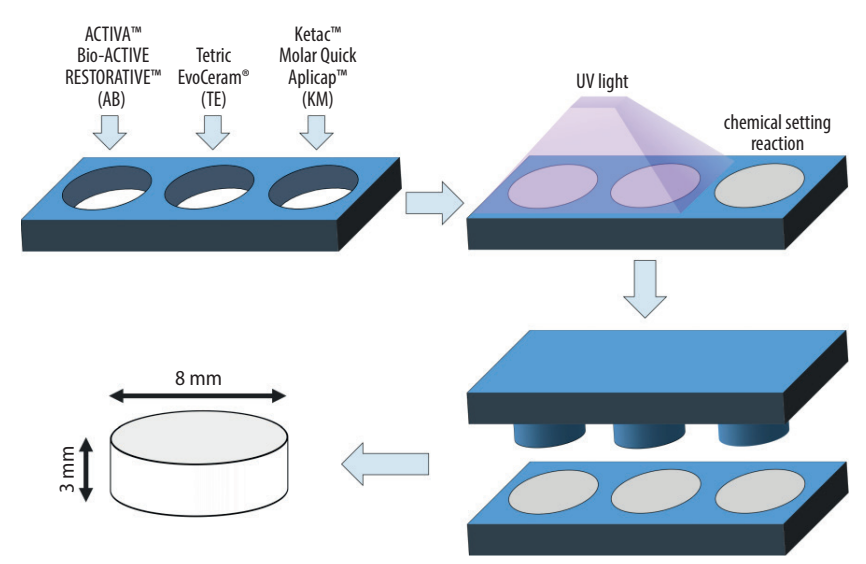

Fig. 1. Schematic illustration of specimens preparation using the 3D forms debris from their surfaces, the specimens were polished with silicone carbide paper of varying grits $(320,600,800$, and 1200), acid-etched for $60 \mathrm{~s}$ with $38 \%$ phosphoric acid (Blue Etch; Cerkamed, Stalowa Wola, Poland), rinsed with water, and blow-dried with air. Immediately after preparation and at the end of the study, the specimens were weighed on a calibrated analytical weight (Mettler AT 200, Mettler-Toledo, Columbus, USA).

\section{The fluoride release test}

The specimens were incubated $\left(37^{\circ} \mathrm{C}, 14\right.$ days) in polypropylene vials containing $4 \mathrm{~mL}$ of deionized (DI) water. As high temperatures can speed up ion movement in a solution and thus give false results, ${ }^{12}$ the specimens were removed from the incubator approx. 30 min before each read-out and left to cool in order to produce similar temperature conditions (average read-out temperature: $21.387^{\circ} \mathrm{C}$ ). The quantity of released fluoride ions ( $\mathrm{ppm}$ ) was measured in DI water with a fluoride-specific electrode (model IJ-F; Ionode Pty Ltd., Tennyson, Australia) coupled with a digital ion analyzer (model CX-601; Elmetron, Zabrze, Poland). The electrode was calibrated daily with a series of standard solutions (50 $\mu \mathrm{M} / \mathrm{L} \mathrm{NaF}$ (949.9 ppb) and $500 \mu \mathrm{M} / \mathrm{L} \mathrm{NaF} \mathrm{(9.499} \mathrm{ppm)),}$ and was washed with fresh DI water and dried with absorbent paper after each analysis. To maintain constant ionic strength, as well as to decomplex the fluoride ions and adjust the $\mathrm{pH}$ of the solution, the same volumes of analyzed DI water and TISAB I were mixed (2:2 mL; 1:1 ratio). During the readouts, the specimens were removed from the vials, rinsed with fresh DI water, dried with absorbent paper, and transferred to new DI water solutions. The DI water measurements for fluoride ion content were carried out daily on the first 7 days and on day 14. The read-out schedule covered days 1-8 and day 14 . No read-outs were carried out between days 8 and 13. The positive controls were Tetric EvoCeram (TE) (Ivoclar Vivadent) and Ketac Molar Quick Aplicap (KM). ACTIVA BioActive-Restorative (AB) served as the experimental group, while the negative control was pure DI water. 


\section{The microscopic analyses}

As the manufacturers' data on the composition of the dental materials chemical is restricted, the authors wanted to provide the characteristics of the structure and composition of both the pre- and post-experimental specimens using scanning electron microscopes (SEM) (SEM/EDX with an energy-dispersive detector (model 1430 VP with XFlash 4010; Leo Electron Microscopy Ltd., Cambridge, UK), VEGA-II SBU (model VG4300780PL; TESCAN, Brno, Czech Republic), Quanta 3D FEG (model 250 with a large-field low-vacuum detector and low-vacuum secondary electron detectors; FEI Europe, Eindhoven, the Netherlands) and X-ray diffraction (XRD) (Philips XPert with X'Celerator scientific detector, Panalytical B.V.; Almelo, the Netherlands; measurement conditions: $\mathrm{CuK} \alpha$ radiation at $40 \mathrm{kV}$ and $30 \mathrm{~mA}, 25-120^{\circ}$ range, $90 \mathrm{~s}$ timing and $0.0167^{\circ}$ step size). An Imager.Z2m confocal microscope with LSM700 laser system (Carl Zeiss Microscopy GmbH, Jena, Germany; measurement conditions: EC Epiplan 20×/0.6 DIC lens (Carl Zeiss Microscopy GmbH), laser wavelength $=405 \mathrm{~nm}$, power of laser $2 \%$, scanning speed 5 , reading frame $2048 \times 2048$, 16 -bit color depth) was also used to present the surfaces of the specimens. Each surface was evaluated at 3 different points, and each measured point was averaged from 2 scans. The assessed PSa (the primary profile's arithmetic mean deviation of all surface heights) index values were averaged using the formula:

$$
P S a=\frac{1}{N_{x} * N_{y}} \sum_{i=1}^{N_{x}} * \sum_{j=1}^{N_{y}} *\left[z\left(x_{i}, y_{j}\right)-P S c\right]
$$

where:

$\mathrm{N}_{\mathrm{x}}, \mathrm{N}_{\mathrm{y}}$ - the number of pixels in X- or Y-direction; $\mathrm{z}$ - the depth of inequalities on the surface; and PSc - the mean height of the elements on the surface.

\section{Statistical analysis}

The statistical analysis was performed using SPSS v. 10.0 for Windows (SPSS Inc., Chicago, USA). The compatibility of the distribution of quantitative variables with normal distribution was checked with the W Shapiro-Wilk test. An analysis of variance (ANOVA) and Scheffé post-hoc test were used to analyze correlations of the variables. In all the tests $\mathrm{p}<0.05$ was considered statistically significant.

\section{Results}

At the end of the study, the mean weight of the AB specimens was lower by $0.76 \%$, while the KM specimens manifested an average weight loss of $3.44 \%$. A mean weight gain of $0.22 \%$ was observed for the TE specimens.

\section{Fluoride release test}

A comparison of the daily mean values of the released fluoride ions from all the tested materials is presented in Fig. 2. The highest quantity of fluoride ions was freed from the KM specimens on days 1-4 (20.698-54.118 ppm; $\mathrm{p}<0.05$ ), followed by $\mathrm{AB}$, with the highest value noted on day 1 (15.552 ppm; $\mathrm{p}<0.05)$. Throughout the observation period, the level of released fluoride ions in the TE specimens (0.370-1.148 ppm) and the control specimens

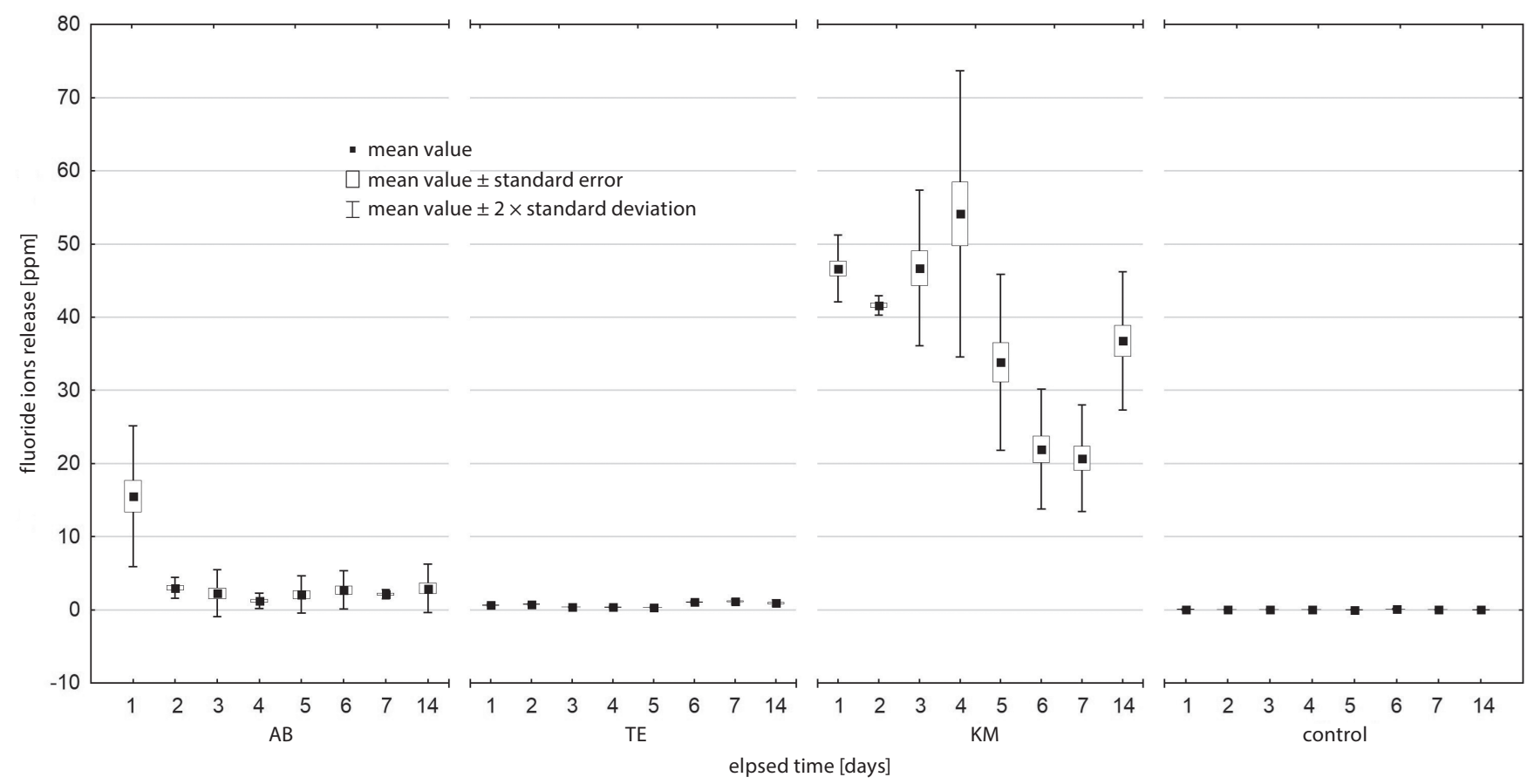

Fig. 2. Daily mean values of the released fluoride ions from dental materials ( $A B, T E, K M)$ and the control (C) 


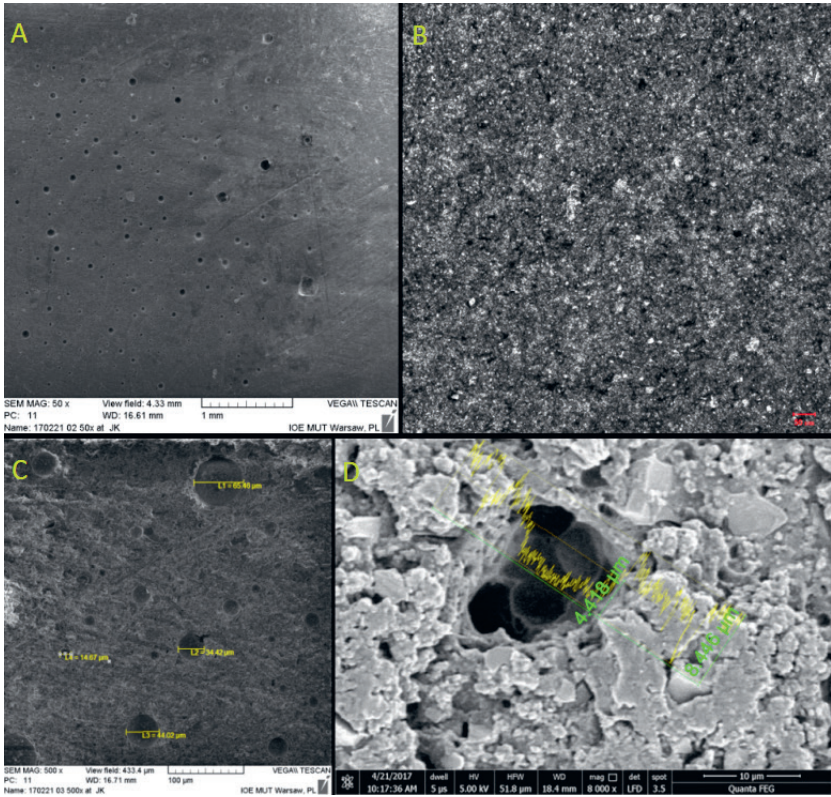

Fig. 3. Images of the pre-experimental AB specimens (A): SEM image of the surface view with visible porosity (VEGA-II SBU; magnification $\times 50$ ); (B) general surface view in confocal microscope, visible pores and roughness of the specimen; (C) SEM image of various in sizes pores in the material (VEGA-II SBU; magnification ×500); (D) SEM high-magnification inset of the pore (Quanta 3D FEG/LVSED; magnification ×8000)

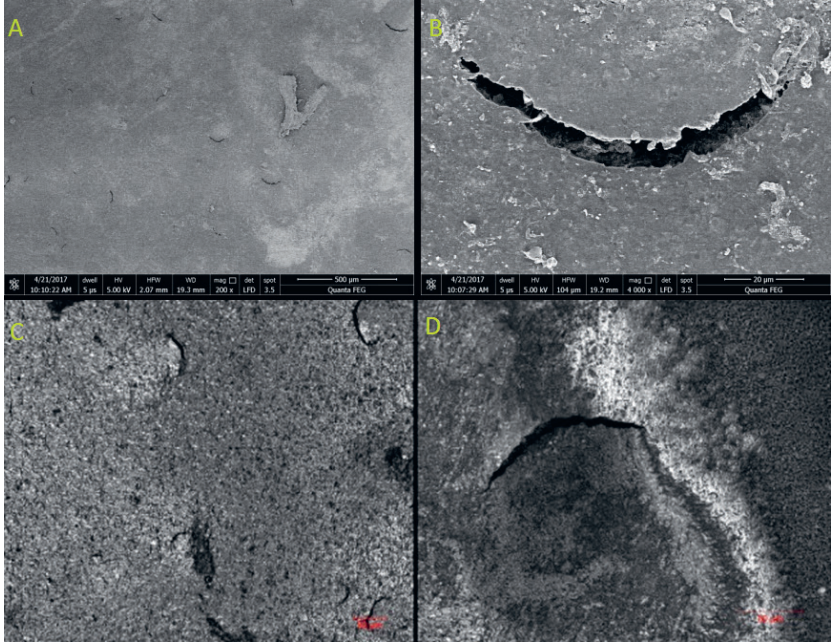

Fig. 4. Images of the post-experimental AB specimens: (A) SEM image of the surface view with visible cracks (Quanta 3D FEG/LFD; magnification $\times 200$ ); (B) SEM high-magnification inset of the crack (Quanta 3D FEG/LFD; magnification $\times 4000)$; (C) general surface view in confocal microscope, visible cracks and smoothness of the specimen; (D) highmagnification inset of the crack in confocal microscope
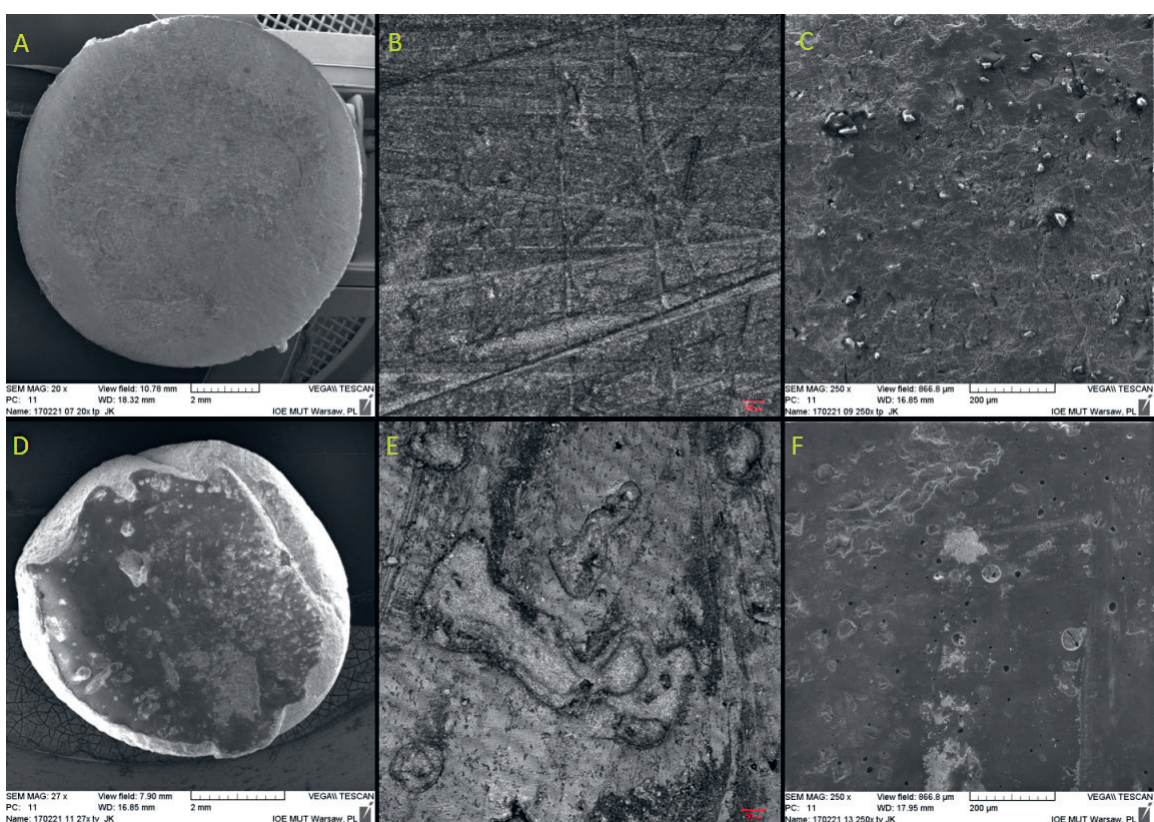

Fig. 5. Images of the TE specimens: preexperimental (A) SEM image of the surface view (VEGA-II SBU; magnification $\times 20$ ); (B) surface view in confocal microscope; $(C)$ distribution of filler particles in the material (VEGA-II SBU; magnification $\times 500$ ); post-experimental (D) general surface view with visible delamination and asperities (VEGA-II SBU; magnification $\times 27$ ); (E) high-magnification view of delaminated surface in confocal microscope; (F) pores and cracks on the specimen's surface (VEGA-II SBU: magnification $\times 250$ )
(0.008-0.122 $\mathrm{ppm})$ were lower than in the other groups. Compared to TE, AB released more fluoride ions on days 1 and 2 ( $\mathrm{p}<0.05)$, with no further significance. Compared to $\mathrm{KM}, \mathrm{AB}$ released significantly fewer fluoride ions $(\mathrm{p}<0.05)$ starting from day 2.

\section{The microscopic analyses}

The pre-experimental surfaces of $A B$ specimens were non-homogeneously studded with pores of various sizes (Fig. 3), while the post-experimental specimens were significantly smoother (PSa index; $\mathrm{p}=0.04$ ), with fewer pores and multiple comma-like micro-cracks (Fig. 4). Compared to the corresponding TE and KM specimens, the pre-experimental $A B$ specimens were significantly smoother (PSa index; $\mathrm{p}<0.001$ ). In addition, the AB specimens were significantly smoother than the TE specimens at the end of the study (PSa index; $\mathrm{p}=0.029$ ).

The pre-experimental TE specimens were quite smooth and homogenous (Fig. $5 \mathrm{~A}-\mathrm{C}$ ), while at the end they were delaminated, with visible pores and asperities (PSa index; $\mathrm{p}=0.027$; Fig. 5 D-F). 


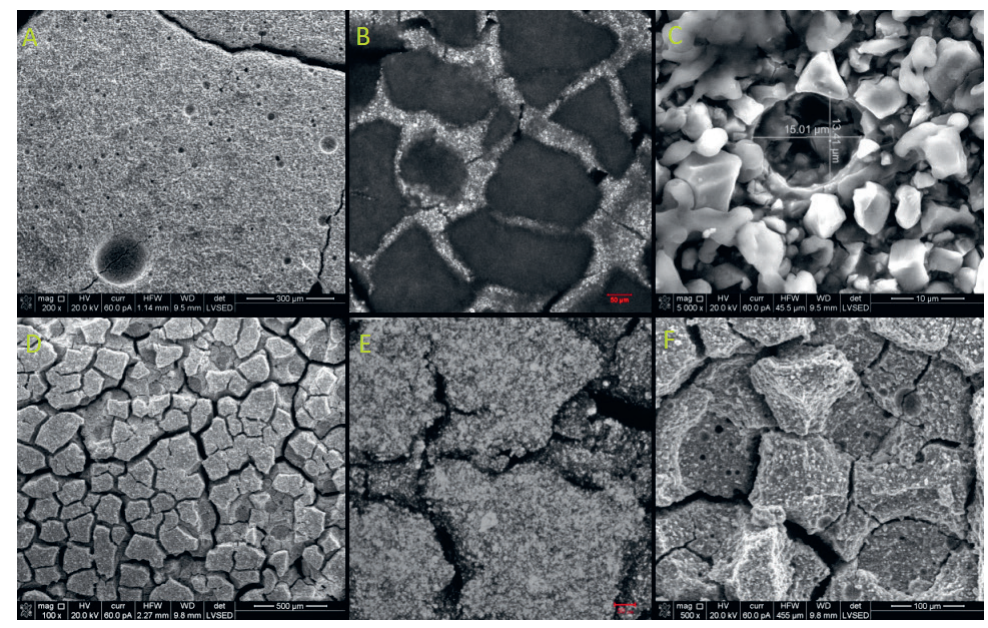

Fig. 6. Images of the KM specimens: pre-experimental (A) SEM image of the surface, visible porosity of the material (Quanta 3D FEG/LVSED; magnification × 200); (B) high-magnification surface view in confocal microscope, visible glass filler in matrix; (C) high-magnification SEM image of the material's inner porosity (Quanta 3D FEG/LVSED; magnification ×5000); post-experimental (D) surface view of the cracked specimen (VEGA-II SBU; magnification X100); (E) high-magnification view of the cracked surface in confocal microscope; (F) pores and cracks on the specimen's surface (Quanta 3D FEG/LVSED; magnification $\times 500$ )
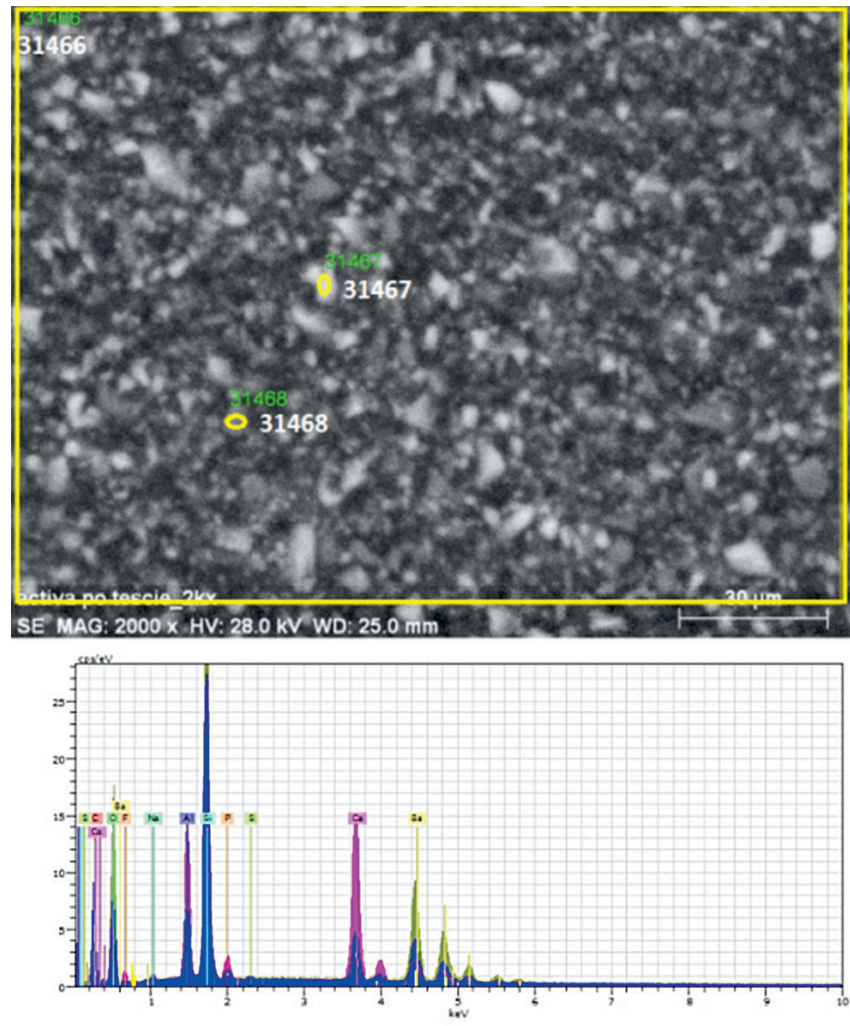

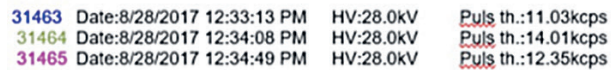
Mass percent (8)

$\begin{array}{lrrrrrrrrrr}\text { Spectrum } & \text { C } & \text { O } & \text { F } & \text { Na } & \text { Al } & \text { Si } & \text { P } & \text { S } & \text { Ca } & \text { Ba } \\ -31463 & 10.50 & 25.81 & 24.64 & 1.01 & 5.01 & 17.34 & 0.79 & 0.19 & 3.84 & 10.85 \\ 31464 & 6.80 & 31.24 & 27.99 & 0.76 & 3.71 & 13.65 & 0.23 & 0.08 & 1.10 & 14.42 \\ 31465 & 5.21 & 19.84 & 30.45 & 1.17 & 9.02 & 15.86 & 1.56 & 0.14 & 11.26 & 5.49 \\ -1.0 a n \text { value: } & 7.50 & 25.63 & 27.70 & 0.98 & 5.91 & 15.62 & 0.86 & 0.14 & 5.40 & 10.26 \\ \text { Sigma: } & 2.72 & 5.70 & 2.91 & 0.20 & 2.77 & 1.86 & 0.67 & 0.05 & 5.26 & 4.50 \\ \text { Sigma mean: } & 1.57 & 3.29 & 1.68 & 0.12 & 1.60 & 1.07 & 0.39 & 0.03 & 3.03 & 2.60\end{array}$

Fig. 7. General composition of AB specimens (SEM/EDS). Area 31465 depicting the main elements building the bioglass. Area 31464 indicating the presence of the inorganic filler

The pre-experimental KM specimens were porous, with irregularly shaped filler particles submerged in the matrix (Fig. 6A-C). After testing, the specimens were less porous and heavily cracked, exposing their inner structure (Fig. 6 D-F).

\section{The X-ray powder diffraction analysis}

The general composition of the pre- and post-experimental specimens was assessed using SEM/EDS and XRD analyses. The AB specimens comprised mainly of fluoride (27.70 mass\%), silicon (15.62 mass\%), aluminum (5.91 mass $\%)$, and calcium (5.40 mass\%). The largest percentage share of the main elements composing the bioglass were found in area 31465, while area 31464 may depict the inorganic filler due to a high share of silicon and barium (Fig. 7). The post-experimental AB specimens showed a loss in fluoride (22.19 mass\%) and natrium (0.89 mass\%). The XRD analysis indicated the presence of calcium fluoride and silicon in all the AB specimens (Fig. 8).

The pre-experimental TE specimens were comprised mainly of fluoride (28.65 mass\%), ytterbium (16.61 mass\%), silicon (16.28 mass\%), and zircon (2.19 mass\%), whereas the post-experimental specimens showed a loss of fluoride (26.78 mass\%) and ytterbium (16.45 mass\%). The XRD analysis showed the presence of calcium, silicon and silicon ytterbium in all the TE specimens (Fig. 9).

The primary constituents of the pre-experimental KM specimens were fluoride (41.55 mass\%), lanthanum (11.83 mass\%), calcium (7.33 mass\%), aluminum (8.24 mass\%), and silicon (6.66 mass\%). A loss of fluoride (41.55 mass\%), aluminum (6.92 mass\%) and silicon (6.07 mass\%) was noted in the post-experimental specimens. The XRD analysis confirmed the presence of calcium and lanthanum oxide in the KM specimens (Fig. 10).

\section{Discussion}

The release of fluoride ions from GICs takes place during their maturation and is diffusion-controlled, meaning that it declines in a linear fashion, reaching a plateau within 10-20 days. ${ }^{13}$ Mazzoui et al. proved that GICs release most of their fluoride content during the first 7 days (12-30 ppm), with a burst effect occurring in the first 24 h. ${ }^{14}$ Our study results showed that the KM specimens 

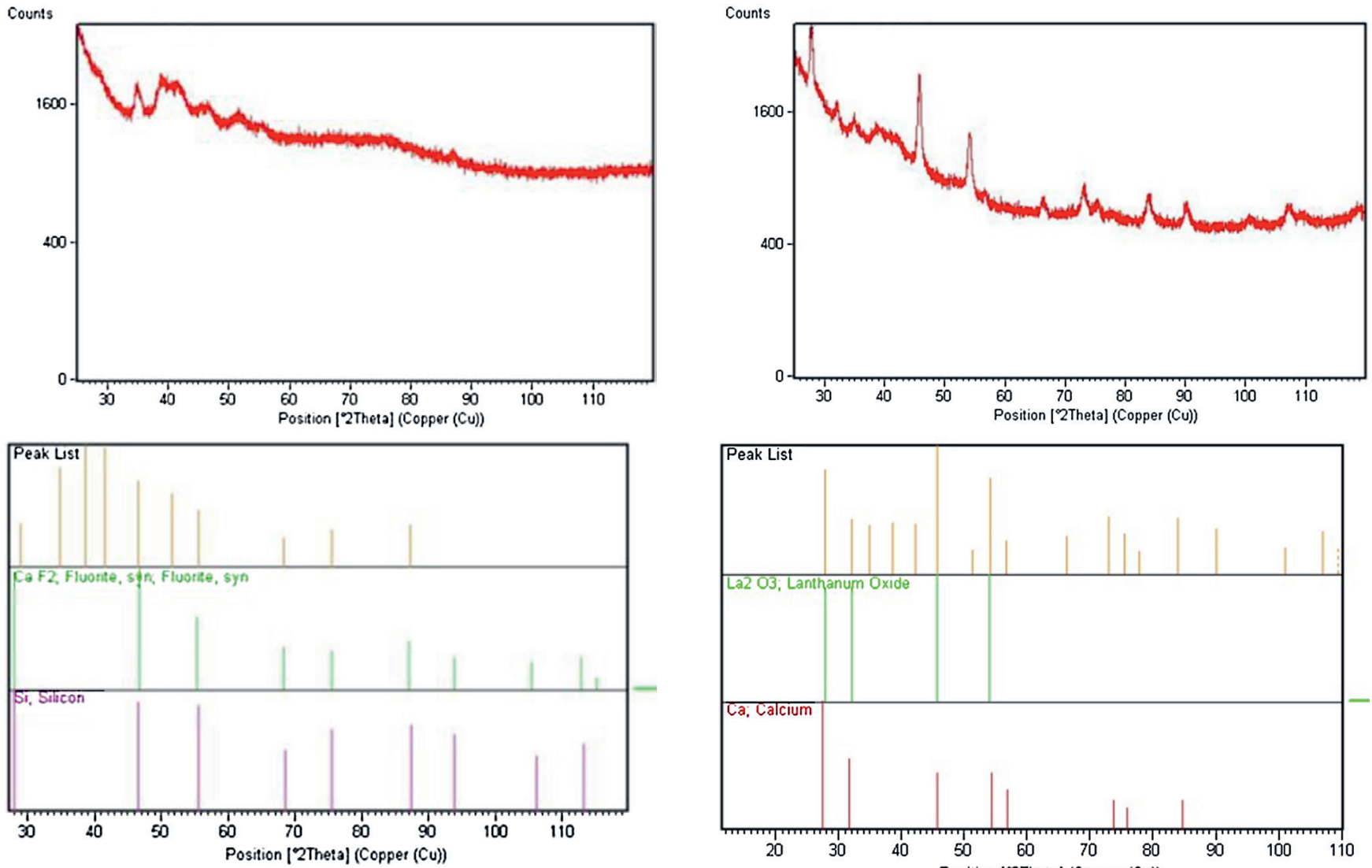

Fig. 8. Composition of $A B$ specimens in XRD analysis

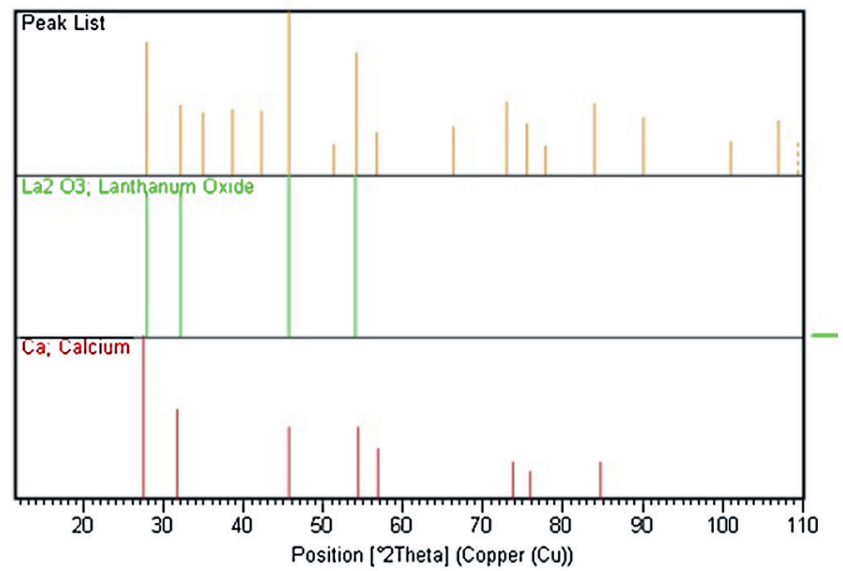

Fig. 10. Composition of KM specimens in XRD analysis
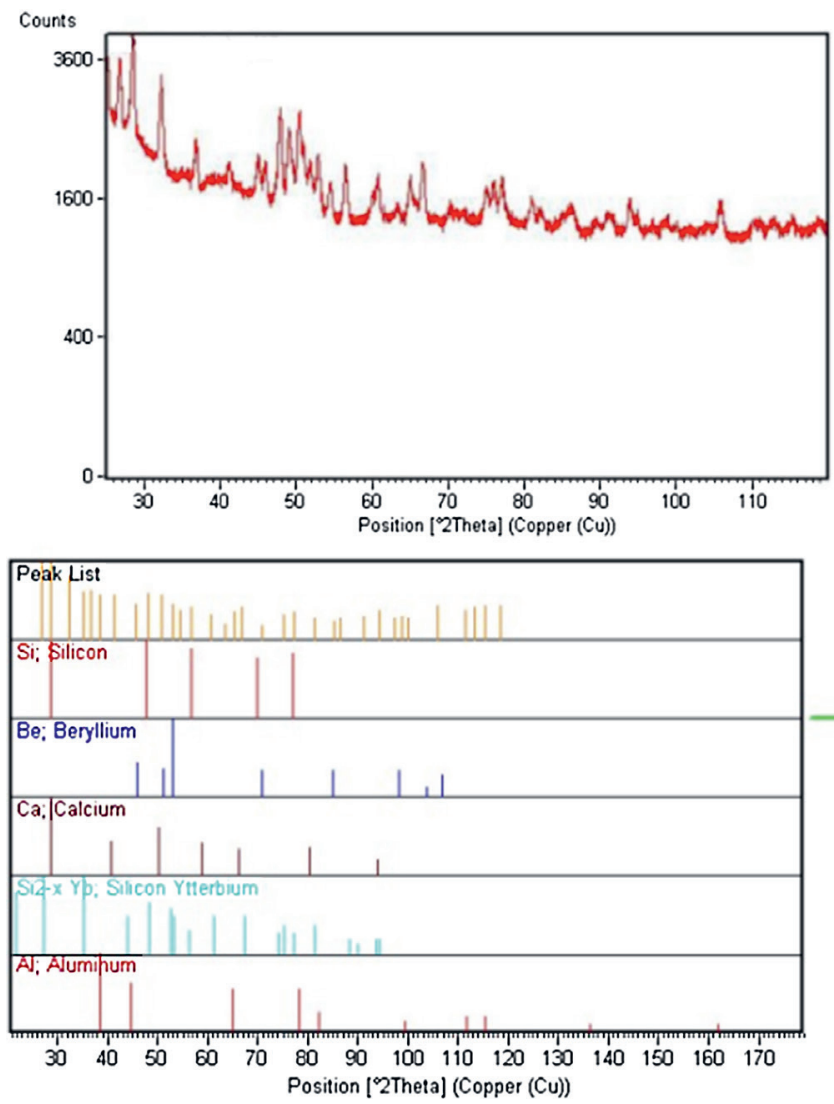

released most of their fluoride ions in the first 4 days (20.698-54.118 ppm), which is compatible with the results reported by Mazzoui et al. Another study indicated that the burst effect of KM was quite low $(1.22 \pm 0.30 \mathrm{ppm})^{15}$ and much lesser than what we observed, possibly due to differences in the measurement conditions and the specimen sizes.

Bioglass dissolution is determined by $\mathrm{Si}-\mathrm{O}-\mathrm{Si}$ bond breakage, which causes a rapid increase in the concentration of fluoride ions between days 0 and 3 , followed by a decline. ${ }^{16,17}$ This suggests that the chemical composition of bioglass has a tremendous impact on its release profile. For instance, Davis et al. demonstrated that long-lasting fluoride release was significantly higher for composites containing bioglass particles rich in silicon. ${ }^{18}$ In a study undertaken by Mneimne et al., bioglass particles rich in phosphate or fluoride were capable of inducing apatite growth faster and at a lower $\mathrm{pH} .{ }^{19}$ As the exact composition and structure of $\mathrm{AB}$ has not been disclosed by the manufacturer, it may be difficult or even impossible to compare its features to other biomaterials. It has been reported that the average daily release of fluoride ions from RMGICs is quite high (4-65 ppm) on the $1^{\text {st }}$ day, declining to approx. $1-2 \mathrm{ppm}$ after 1 week. ${ }^{13,16,20}$ Kishore et al. stated that RMGICs were more efficient in their ability to release than GICs $(6.7 \pm 0.158 \mathrm{ppm}$ vs $2.9 \pm 0.158 \mathrm{ppm}),{ }^{16}$

Fig. 9. Composition of TE specimens in XRD analysis 
whereas Kucukyilmaz et al. and Rama Rao et al. stated they were significantly less efficient. ${ }^{5,20}$ In our study, the bioglass-reinforced RMGIC (AB) obtained the highest level of freed fluoride ions on the $1^{\text {st }}$ day $(15.5 \mathrm{ppm})$, which later decreased to a continuous plateau of 1.2-3.0 ppm. Compared to KM, its release profile was significantly lower. On this basis, our null hypothesis had to be rejected. Apart from obvious differences in the chemical composition of the 2 materials, we believe that this result may also depend on the storage media, as dental materials kept in DI water show lower ionic flow compared to the $\mathrm{pH}$-cycling method. ${ }^{4}$ The $\mathrm{pH}$ values of the solutions used may also have had an impact on the ion release. ${ }^{21}$ Garoushi et al., who also analyzed $\mathrm{AB}$ in similar conditions to those in this study, observed that it released significantly fewer fluoride ions compared to other RMGICs. ${ }^{22}$ They also pointed out a tendency for this material to liberate the most ions in the first $24 \mathrm{~h}$ (approx. $1.5 \mathrm{ppm}$ ), followed by stabilization at a lower level, which is in agreement with our results. Similar conclusions were provided by May and Donly, who found that $A B$ released significantly less fluoride than another RMGIC (Vitremer) throughout their observation period (31 days). ${ }^{23}$ Contrary to both Garoushi et al. and May and Donly, we obtained a higher level of released fluoride after $24 \mathrm{~h}$ (15.552 ppm vs $1.5 \mathrm{ppm}^{23}$ vs $1.920 \mathrm{ppm}^{23}$ ), which may be due to different read-out equipment and study conditions. Gandolfi et al. support the idea that the presence of hydrophilic resins, such as HEMA or triethylene glycol dimethacrylate (TEGDMA), could lead to hydrolytic disintegration of bioglass particles. Weight reduction of their experimental composites was attributed to the release of calcium and hydroxyl ions. ${ }^{8}$ Our study supports their conclusions, as we observed a $0.76 \%$ average mass reduction in the $\mathrm{AB}$ specimens. Most of the polymer resins released extremely low or even no fluoride ions (less than 0.02-2 ppm within 30-60 days), ${ }^{13}$ which was confirmed in this study (TE; 1.0 ppm).

The SEM/EDS and XRD analyses helped to define only the primary composition of the pre- and post-experimental specimens, as their chemical structure proved to be complex. Despite numerous trials and methodologies, determination of the exact compositions could not be satisfactorily concluded. The SEM analysis showed the presence of pores in the pre-experimental AB specimens, which resemble the inner structure of GICs and may allow water flow through the material. Fewer pores, multiple cracks and delamination of the post-experimental specimens suggested that the material had decomposed in DI water. Even though all the tested materials were kept in a moist and warm environment, their disintegration modes clearly differed from one another. Polymer resins are susceptible to premature failure due to the formation of cracks, micro-cracks and delaminations, which develop in response to various stimuli. Moisture plays an important role in their fatigue, as they are prone to water uptake. Moreover, thermal stress occurs in response to temperature fluctuations throughout the time they are in the oral cavity, even without additional mechanical loading. ${ }^{24}$ The development of thermal stress may also depend on the matrix reinforcement and any inhomogeneity within their structure. For instance, resin composites reinforced with glass microspheres were subject to accelerated degradation. ${ }^{25}$ The absorbed water, along with temperature changes, may contribute to hygrothermal failure, in which the structure of the polymer is affected by the formation of internal stress leading to further cracking. ${ }^{24}$ As a result, we expected the post-experimental TE specimens to be cracked, non-homogeneous and delaminated. Presumably, the presence of the comma-like micro-cracks in the post-experimental AB specimens may also be a result of hygrothermal failure developing within the bioglass-reinforced porous structure of RMGIC.

\section{Conclusions}

Within the limitations of this in vitro study, it may be concluded that the fluoride ion release profile of the novel restorative material ACTIVA BioActive-Restorative was lower than the GIC Ketac Molar Quick Aplicap, but significantly higher than that of the nanohybrid restorative polymer resin Tetric EvoCeram.

\section{References}

1. Hench LL, Splinter RJ, Allen WC, Greenlee TK. Bonding mechanisms at the interface of ceramic prosthetic materials. J Biomed Mater Res. 1971;5(6):117-141.

2. Mousavinasab SM, Khoroushi M, Keshani F, Hashemi S. Flexural strength and morphological characteristics of resin-modified glassionomer cement containing bioactive glass. J Contemp Dent Pract. 2011;12(1):41-46.

3. ten Cate JM. Contemporary perspective on the use of fluoride products in caries prevention. Brit Dent J. 2013;214(3):161-167.

4. Garcez RM, Buzalaf MAR, de Araújo PA. Fluoride release of six restorative materials in water and $\mathrm{pH}$-cycling solutions. J Appl Oral Sci. 2007;15(5):406-411.

5. Kucukyilmaz E, Savas S, Kavrik F, Yasa B, Botsali MS. Fluoride release/ recharging ability and bond strength of glass ionomer cements to sound and caries-affected dentin. Niger J Clin Pract. 2017;20(2): 226-234.

6. Nicholson JW, Czarnecka B. The biocompatibility of resin-modified glass-ionomer cements for dentistry. Dent Mater. 2008;24(12):1702-1708.

7. Van Landuyt KL, Snauwaert J, Peumans M, De Munck J, Lambrechts P, Van Meerbeek B. The role of HEMA in one-step self-etch adhesives. Dent Mater. 2008;24(10):1412-1419.

8. Gandolfi MG, Taddei P, Siboni F, Modena E, De Stefano ED, Prati C. Biomimetic remineralization of human dentin using promising innovative calcium-silicate hybrid "smart" materials. Dent Mater. 2011;27(11): 1055-1069.

9. McCabe JF, Yan Z, AI Naimi OT, Mahmoud G, Rolland SL. Smart materials in dentistry: Future prospects. Dent Mater J. 2009;28(1):37-43.

10. Khvostenko D, Hilton TJ, Ferracane JL, Mitchell JC, Kruzic JJ. Bioactive glass fillers reduce bacterial penetration into marginal gaps for composite restorations. Dent Mater. 2016;32(1):73-81.

11. Pameijer $\mathrm{CH}$, Garcia-Godoy F, Morrow BR, Jefferies SR. Flexural strength and flexural fatigue properties of resin-modified glass ionomers. J Clin Dent. 2015;26(1):23-27.

12. Yan Z, Sidhu SK, Mahmoud GA, Carrick TE, McCabe JF. Effects of temperature on the fluoride release and recharging ability of glass ionomers. Oper Dent. 2007;32(2):138-143. 
13. Wiegand A, Buchalla W, Attin T. Review on fluoride-releasing restorative materials: Fluoride release and uptake characteristics, antibacterial activity and influence on caries formation. Dent Mater. 2007;23(3):343-362.

14. Mazzaoui SA, Burrow MF, Tyas MJ. Fluoride release from glass ionomer cements and resin composites coated with a dentin adhesive. Dent Mater. 2000;16(3):166-171.

15. Basso GR, Della Bona Á, Gobbi DL, Cecchetti D. Fluoride release from restorative materials. Braz Dent J. 2011;22(5):355-358.

16. Kishore G, Sai-Sankar AJ, Pratap-Gowd M, Sridhar M, Pranitha K Sai-Krishna VS. Comparative evaluation of fluoride releasing ability of various restorative materials after the application of surface coating agents: An in vitro study. J Clin Diagn Res. 2016;10(12):ZC38-ZC41.

17. Shah FA, Brauer DS, Hill RG, Hing KA. Apatite formation of bioactive glasses is enhanced by low additions of fluoride but delayed in the presence of serum proteins. Mater Lett. 2015;153:143-147.

18. Davis HB, Gwinner F, Mitchell JC, Ferracane JL. Ion release from, and fluoride recharge of a composite with a fluoride-containing bioactive glass. Dent Mater. 2014;30(10):1187-1194.
19. Mneimne M, Hill RG, Bushby AJ, Brauer DS. High phosphate content significantly increases apatite formation of fluoride-containing bioactive glasses. Acta Biomater. 2011;7(4):1827-1834.

20. Rama Rao SB, Patri G, Agnihotri Y, Balagopal S. Fluoride and restorative materials. Int J Contemp Dent. 2011;2(3):159-164.

21. Fúcio SB, De Paula AB, Sardi JC, Duque C, Correr-Sobrinho L, PuppinRontani RM. Streptococcus mutans biofilm influences on the antimicrobial properties of glass ionomer cements. Braz Dent J. 2016;27(6):681-687.

22. Garoushi S, Vallittu PK, Lassila L. Characterization of fluoride releasing restorative dental materials. Dent Mater J. 2018;37(2):293-300.

23. May E, Donly KJ. Fluoride release and re-release from a bioactive restorative material. Am J Dent. 2017;30(6):305-308.

24. Awaja F, Zhang S, Tripathi M, Nikiforov A, Pugno N. Cracks, microcracks and fracture in polymer structures: Formation, detection, autonomic repair. Prog Mater Sci. 2016;83:536-573.

25. Awaja F, Arhatari B, Wiesauer K, Leiss E, Stifter D. An investigation of the accelerated thermal degradation of different epoxy resin composites using X-ray microcomputed tomography and optical coherence tomography. Polym Degrad Stab. 2009;94(10):1814-1824. 